\section{Two successive partial trisomies for opposite halves of chromosome 22 in a mother with a balanced translocation}

A 30-year-old white female, G2, P1, delivered a $2000 \mathrm{~g}$ female infant, measuring $42.5 \mathrm{~cm}$, with the following anomalies: unilateral cleft lip with cleft palate, low set ears, microcephaly, simian creases, and rocker bottom feet. The child died a cardiac death 2 days after birth. At necropsy, the heart showed a truncus arteriosus with ventricular and atrial septal defects. There was also an absent left kidney. There was neither anal atresia nor micrognathia. Chromosomal analysis showed 46,XX, +22 (q13 $\rightarrow$ qter) (figure a). Karyotyping of the child's parents showed the father to be $46, \mathrm{XY}$ and the mother to be a balanced translocation carrier, 46,XX,t $(7 ; 22)$ (p22;q13) (figure b).

A diagnostic amniocentesis was done at 17 weeks menstrual age in her next pregnancy and showed a fetal chromosomal complement of $47, \mathrm{XX},+\operatorname{del}(22)(\mathrm{q} 13)$ (figure c). The fetus had received both maternal chromosomes 22 through non-disjunction and had a partial trisomy 22 for that region of the chromosome not represented in the first child described in this report. The parents elected to continue the pregnancy and at 36 weeks, after spontaneous labour, a female infant was delivered. This infant weighed $2130 \mathrm{~g}$ and had multiple congenital anomalies. These included a flattened bridge of the nose with hypertelorism and marked microphthalmia, preauricular sinus, low set ears, and rockerbottom feet. A soft systolic murmur was heard. The palate was intact and the genitalia were normal. The anus was patent. Progressive respiratory distress ensued and the infant died after $5 \frac{1}{2}$ hours. Additional findings at necropsy included a bicuspid aortic valve, patent foramen ovale, and pulmonary atelectasis with hyaline membrane disease. Blood and skin for chromosomal analysis confirmed the prenatal diagnosis.

The clinical features of our two patients were compared with other reported patients who had partial or complete trisomy for chromosome $22 .{ }^{1}$ The only positive clinical features shared by our two newborns were low set ears and failure to thrive. Other characteristic findings, such as cleft palate, congenital heart disease, microcephaly, microphthalmia, and preauricular sinuses, ${ }^{2}$ were subdivided between the two (see above description). This is of interest because together our two infants represent a total trisomy owing to non-overlapping areas of chromosome 22. Neither child had coloboma, anal atresia, or micrognathia, commonly associated with the cat eye syndrome, which has been attributed to partial trisomy $22 .^{2}$ These comparisons are valuable, not only to see where our patients fit in the described phenotypic spectrum, but also to highlight the difficulty in making a clinical diagnosis without clear cytogenetic support.

This report includes the first clinical description of a partial trisomy 22 for the distal end of the chromosome.

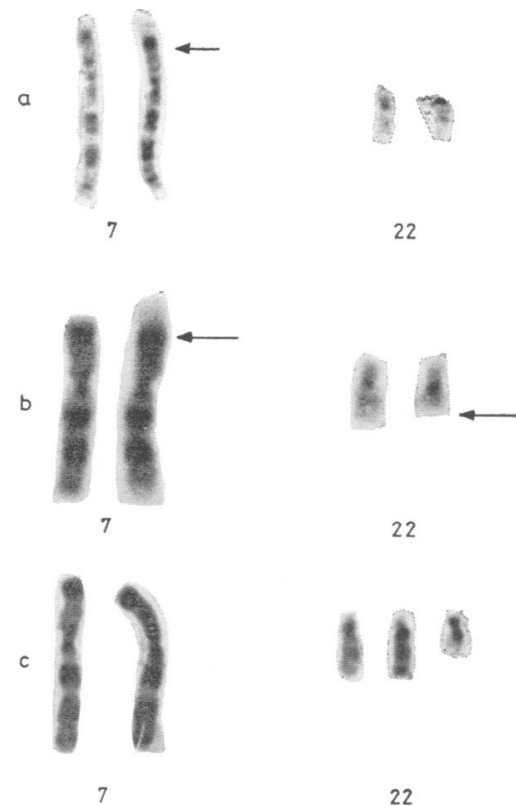

FIGURE (a) Partial karyotype of case 1 showing extra chromatin material from chromosome 22 on distal short arm of chromosome $7(46, X X,+22(q 13 \rightarrow$ qter $))$.

(b) Partial karyotype of mother showing balanced translocation of chromatin from distal portion of chromosome 22 onto distal short arm of chromosome 7 $(46, X X, t(7 ; 22)(p 22 ; q 13))$. (c) Partial karyotype of case 2 showing extra deleted chromosome $22(47, X X,+$ del (22) (q13)).

However, the most interesting and most important features of this communication are that the origin and identification of the extra chromosomal material are reliably fixed.

Richard P Bendel,* Shari Baldinger,* Cynthia Millard, $\dagger$ and Diane C Arthur $\dagger$ * Department of Obstetrics and Gynecology, Hennepin County Medical Center, Minneapolis, Minnesota 55415;

and $\dagger$ Department of Laboratory Medicine and Pathology, University of Minnesota Health Sciences Center, Minneapolis, Minnesota 55455, USA

\section{References}

1 Pai GS, Thomas GH, Leonard CO, Ward JC, Valle DL, Pyeritz RE. Syndromes due to chromosomal abnormalities: partial trisomy 22, interstitial deletion of the long arm of 13, and trisomy 8. Johns Hopkins Med J 1979;145: 162-9.

2 de Grouchy J, Turleau C. Clinical atlas of human chromosomes. New York: Wiley, 1977:210-6.

Requests for reprints to Dr Richard P Bendel, Department of Obstetrics and Gynecology, Hennepin County Medical Center, 701 Park Avenue South, Minneapolis, Minnesota 55415, USA. 